\title{
The Distribution-Free Newsboy Problem with Multiple Discounts and Upgrades
}

\author{
Ilkyeong Moon, ${ }^{1}$ Dong Kyoon Yoo, ${ }^{2}$ and Subrata Saha ${ }^{1}$ \\ ${ }^{1}$ Department of Industrial Engineering, Seoul National University, Seoul 08826, Republic of Korea \\ ${ }^{2}$ Quality Management Department, LG Electronics, Seoul 07336, Republic of Korea \\ Correspondence should be addressed to Subrata Saha; subrata.scm@gmail.com
}

Received 28 March 2016; Accepted 26 July 2016

Academic Editor: Paolo Crippa

Copyright (c) 2016 Ilkyeong Moon et al. This is an open access article distributed under the Creative Commons Attribution License, which permits unrestricted use, distribution, and reproduction in any medium, provided the original work is properly cited.

\begin{abstract}
Most papers on the newsboy problem assume that excess inventory is either sold after discount or discarded. In the real world, overstocks are handled with multiple discounts, upgrades, or a combination of these measures. For example, a seller may offer a series of progressively increasing discounts for units that remain on the shelf, or the seller may use incrementally applied innovations aimed at stimulating greater product sophistication. Moreover, the normal distribution does not provide better protection than other distributions with the same mean and variance. In this paper, we find the differences between normal distribution approaches and distribution-free approaches in four scenarios with mean and variance of demand as the only available data to decision-makers. First, we solve the newsboy problem by considering multiple discounts. Second, we formulate and solve the newsboy problem by considering multiple upgrades. Third, we formulate and solve a mixed newsboy problem characterized with multiple discounts and upgrades. Finally, we extend the model to solve a multiproduct newsboy problem with a storage or a budget constraint and develop an algorithm to find the solutions of the models. Concavity of the models is proved analytically. Extensive computational experiments are presented to verify the robustness of the distribution-free approach. The results show that the distribution-free approach is robust.
\end{abstract}

\section{Introduction}

In general selling situations, the information on demand distribution is limited. Often, sellers are only provided with an educated guess of the mean and the variance. Then, they will use the normal distribution of the demand to determine the proper inventory levels. However, the normal distribution for demand does not provide the best protection for the occurrence of other distributions with the same mean and the same variance. In a classic paper, Scarf [1] addressed the newsboy problem in which the mean $\mu$ and the variance $\sigma^{2}$ of demand were given, whereas assumptions on the distribution of demand were not available. Taking a conservative approach, Scarf modeled the problem by finding the order quantity that maximizes the expected profit and compared the result with the worst possible distribution of demand as characterized with the mean $\mu$ and the variance $\sigma^{2}$. Through a beautiful, but lengthy, mathematical argument, Scarf showed that the worst demand distribution is positive at two points and developed the min-max distribution-free approach as a closed-form expression for deriving the optimal order quantity.

Gallego and Moon [2] simplified the proof of Scarf's [1] ordering rule for the newsboy problem. Moon and Gallego [3] applied the approach to several inventory models including a periodic review model. Moon and Choi [4] solved the distribution-free continuous-review inventory model with a service-level constraint. Moon and Choi [5] provided the make-to-order and make-in-advance models using the distribution-free procedure. Moon and Choi [6] improved the continuous-review inventory model by simultaneously optimizing the order quantity and reorder point. Ouyang and $\mathrm{Wu}$ [7] developed models for reduction of the continuousreview inventory system. They also applied the distributionfree approach to each model and proved its robustness. Hariga and Ben-Daya [8] developed optimal reduction procedures in the procurement lead time duration and applied the distribution-free approach to several stochastic inventory 
models such as the continuous- and periodic-review models with a mixture of backorders and lost sales and the base stock. Ouyang and Chang [9] applied a minimax distribution-free procedure for mixed inventory models with variable lead time and fuzzy lost sales. Tajbakhsh [10] derived closedform expressions for the model of Moon and Choi [4]. Numerous models have been studied using the distributionfree approach [11-16]. For more details, one can refer to an extensive review of the literature provided by Qin et al. [17]. In this study, we verify the robustness of the distribution-free approach where multiple discounts or upgrades are used to sell products and study the impact of the distribution-free approach under a storage or a budget constraint.

The classical newsboy problem is designed to find the product order quantity that maximizes the expected profit in a single-period, probabilistic demand framework. Hadley and Whitin [18] addressed the newsboy model under the assumption that an excess inventory from an order quantity larger than the realized demand is either sold with a single discount or discarded. Following the work, various versions of pricing and discount strategies have been discussed to explore the characteristics of the newsboy problem. Readers can refer to some major research performances by Carrizosa et al. [19], Li et al. [20], and Ye and Sun [21]. Recently, Petruzzi and Dada [22] addressed a comprehensive review and meaningful extensions for the pricing decision in the newsboy problem. However, multiple progressive discounts in a newsboy framework have received only minor attention despite their common appearances in apparel industry where discounts get steeper as the season draws to an end [23]. Khouja [24] developed a model in which multiple discounts are used progressively to sell excess inventory with normally distributed demand. Later, Khouja and Mehrez [25] considered an extension in which a space or budget constraint is placed on a group of items. Khouja [26] extended the newsboy problem by considering price-dependent demand and multiple discounts to sell excess inventory. Such extensions have been thoroughly studied for deterministic economic-order quantity models. In this paper, we apply the distribution-free approach to the basic model of Khouja [24] and consider the situation in which more than one type of stock-keeping unit is stocked for a single-period demand.

Considerable research has been conducted to analyze the multiproduct newsboy problems with constraints [18, 27-29]. Among those works, Hadley and Whitin [18] were the first to consider a single constraint to a multiproduct newsboy problem. Nahmias and Schmidt [30] proposed a multiproduct newsboy problem with stochastic demand subject to linear and deterministic constraints on space or budget. H.-S. Lau and A. H.-L. Lau [31] extended the constrained newsboy problem to general demand distributions. Erlebacher [32] developed optimal and heuristic solutions for the capacitated newsboy problem. Although budget and storage constraints as well as price discounts are common features in numerous problems, few researchers have considered both a constraint and a discount in a newsboy model. In this paper, we extend the multiproduct newsboy problem to the situation in which the newsboy problem is characterized by a budget constraint and multiple discounts to stimulate demand under the traditional and distribution-free approaches and consider the cost of improving the quality of the product. Nonprice competition is found in many industries, and, as a key nonprice competitive feature in the majority of industries, improved product quality has received intensive attention, especially in terms of investment [33]. Quality upgrading improves firm's ability to serve more consumers because quality products appeal to wealthier consumers. We refer the reader to Garvin [34] for an excellent summary of quality characterization. Also, since 1970, Toyota Motor Co. Ltd. began cooperating with its supplier to improve product quality [35]. In an increasingly competitive global environment, there is growing evidence that investment in quality improvements, such as applying, renewing, updating, accumulating, and redeeming, enhances customer satisfaction and builds long-term relationships between sellers and customers [36]. However, most of the studies on quality improvement fall under the supply chain framework $[37,38]$. Due to these extensions we make, our model is applicable not only to the apparel industry, but also to the computer, telecommunication machine, college textbooks, and video game industries among others. In each case, we are not able to estimate the exact price because an upgrade cost may be incurred due to growing technology. However, one must note that upgrade cost does not necessarily translate into increased demand. Therefore, we keep the price fixed and formulate the problem with multiple upgrades. To the best of our knowledge, this type of quality improvement strategy has received little attention in studies of the newsboy problem. Moreover, we consider the effect of both multiple discounts and upgrades on profitability.

In this study, we extend the newsboy problem to consider the situation in which the seller applies progressive multiple discounts, upgrades, or their combination, to enhance product flow and profit. We elongate the newsboy problem by considering four different scenarios and compare the effects of the distribution-free approach with the traditional distribution approach in single- and multiple-product environments. We also examine the effect of a budget or a storage constraint. The remainder of the paper is organized as follows. Section 2 analyzes the behavior of newsboy problems for demand distribution of a single product in three different scenarios. We present the theoretical background for obtaining the order quantities under the worst- and best-case scenarios. Section 3 discusses the newsboy problem with progressive multiple discounts or upgrades under a budget or a storage constraint. Section 4 presents computational examples to illustrate all the models. Finally, Section 5 addresses final remarks as well as suggestions for future research and extensions of the obtained results.

\section{Mathematical Models}

The following notations are used to establish mathematical models:
$j:$ the discounted (or upgraded) index.
$n$ : the number of discounts (or upgrades).
$P$ : the unit selling price. 
$C$ : the unit cost.

$S$ : the salvage value.

$X$ : the quantity demanded, a random variable $(X>$ $0)$.

$f(X)$ : the probability density function of $X$.

$F(X)$ : the cumulative distribution function of $X$.

Q: the order quantity.

$\mu$ : the expected demand.

$\sigma:$ the standard deviation of demand.

$d_{j}$ : the $j$ th discounted rate $\left(0 \leq d_{j} \leq 1\right), 0=d_{0}<$ $d_{1}<d_{2}<\cdots<d_{n}$.

$P_{j}$ : the $j$ th discounted selling price, $P_{j}=\left(1-d_{j}\right) P$.

$u_{j}$ : the $j$ th upgraded rate $\left(0 \leq u_{j} \leq 1\right), 0=u_{0}<u_{1}<$ $u_{2}<\cdots<u_{n}$.

$C_{j}$ : the $j$ th upgraded cost, $C_{j}=\left(1+u_{j}\right) C$.

$t_{j}$ : the fraction of the realized demand at the original price (or cost) that can additionally be sold by discounting (or upgrading) the product to price $P_{j}$ (or $\left.\operatorname{cost} C_{j}\right)\left(0<t_{j}<1\right)$.

2.1. The Newsboy Problem with Progressive Multiple Discounts. We focus on the special case where the additional quantity that can be sold at the $j$ th discount price is directly proportional to the quantity realized at the regular price. In other words, if the product has high demand at the regular price, then discounting the product should result in proportionally additional demand and vice versa. If we refer to the time of the $j$ th discount as the $j$ th discount period, then statistically the demand in each discount period is perfectly and positively correlated with the demand in the first (nondiscount) period. We assume that the salvage value of the product is the $n$th discount price, and the penalty for not satisfying demand is zero. Here, the profit function $\left(\pi_{d}^{N}(Q)\right)$ can be represented as follows:

$$
\begin{aligned}
& \pi_{d}^{N}(Q) \\
& = \begin{cases}\alpha_{0} t_{0} Q & \text { if } \frac{\mathrm{Q}}{V_{0}} \leq X \\
\alpha_{0} t_{0} X+\alpha_{1}\left(Q-V_{0} X\right) & \text { if } \frac{Q}{V_{1}} \leq X<\frac{Q}{V_{0}} \\
\alpha_{0} t_{0} X+\alpha_{1} t_{1} X+\alpha_{2}\left(Q-V_{1} X\right) & \text { if } \frac{Q}{V_{2}} \leq X<\frac{Q}{V_{1}} \\
\vdots & \vdots \\
X \sum_{j=0}^{n-1} \alpha_{j} t_{j}+\alpha_{n}\left(Q-V_{n-1} X\right) & \text { if } 0 \leq X<\frac{Q}{V_{n-1}},\end{cases}
\end{aligned}
$$

where $\alpha_{j}=P_{j}-C, V_{j}=1+\sum_{k=1}^{j} t_{k}, t_{0}=1$, and $V_{0}=1$. The expected value of $\pi_{d}^{N}(Q)$ is

$$
\begin{aligned}
& \Pi_{d}^{N}(Q) \\
& =\int_{Q / V_{0}}^{\infty} \alpha_{0} t_{0} Q f(X) d X \\
& \quad+\int_{Q / V_{1}}^{Q / V_{0}}\left[\alpha_{0} t_{0} X+\alpha_{1}\left(Q-V_{0} X\right)\right] f(X) d X+\cdots \\
& \quad+\int_{0}^{Q / V_{n-1}}\left[X \sum_{j=0}^{n-1} \alpha_{j} t_{j}+\alpha_{n}\left(Q-V_{n-1} X\right)\right] f(X) d X .
\end{aligned}
$$

The necessary condition for $Q$ to be optimal is given by

$$
\frac{d \Pi_{d}^{N}(Q)}{d Q}=\alpha_{0}-\sum_{j=0}^{n-1}\left(P_{j}-P_{j+1}\right) F\left(\frac{Q}{V_{j}}\right)=0 .
$$

The second-order derivative of $\Pi_{d}^{N}(Q)$ is given by $d^{2} \Pi_{d}^{N}(Q) / d Q_{2}=\sum_{j=0}^{n-1}\left(1 / V_{j}\right)\left(P_{j+1}-P_{j}\right) f\left(Q / V_{j}\right)$. Because $f(X) \geq 0$ and $P_{j+1}-P_{j} \leq 0, d^{2} \Pi_{d}^{N}(Q) / d Q_{2} \leq 0$ for $Q \geq 0$ and hence $\Pi_{d}^{N}(Q)$ is concave.

The normal distribution does not provide the best protection against the occurrence of other distributions with the same mean and variance. Therefore, we formulate and solve the distribution-free newsboy problem with multiple discounts. In this case, the profit function $\left(\pi_{d}^{W}(Q)\right)$ can be obtained as

$$
\pi_{d}^{W}(Q)= \begin{cases}\alpha_{0} t_{0} Q & \text { if } \frac{Q}{V_{0}} \leq X \\ \alpha_{0} t_{0} Q-d_{1} P\left(Q-V_{0} X\right) & \text { if } \frac{Q}{V_{1}} \leq X<\frac{Q}{V_{0}} \\ \alpha_{0} t_{0} Q-d_{1} P\left(Q-V_{0} X\right)-\left(d_{2}-d_{1}\right) P\left(Q-V_{1} X\right) & \text { if } \frac{Q}{V_{2}} \leq X<\frac{Q}{V_{1}} \\ \vdots & \vdots \\ \alpha_{0} t_{0} Q-P \sum_{j=1}^{n}\left(d_{j}-d_{j-1}\right)\left(Q-V_{j-1} X\right) & \text { if } 0 \leq \frac{Q}{V_{n-1}} .\end{cases}
$$


The expected value of $\pi_{d}^{W}(Q)$ is given by

$$
\begin{aligned}
\Pi_{d}^{W}(Q)= & \alpha_{0} t_{0} Q-P \sum_{j=1}^{n}\left(d_{j}-d_{j-1}\right) E\left(Q-V_{j-1} X\right)^{+} \\
= & \alpha_{0} t_{0} Q \\
& -P \sum_{j=1}^{n}\left(d_{j}-d_{j-1}\right) V_{j-1} E\left(\frac{Q}{V_{j-1}}-X\right)^{+} .
\end{aligned}
$$

Observing that $(Q-X)^{+}=(Q-X)+(X-Q)^{+}$, we can write the expected profit as

$$
\begin{aligned}
\Pi_{d}^{W}(Q)= & \mu P \sum_{j=1}^{n}\left(d_{j}-d_{j-1}\right) V_{j-1} \\
& -\left[P \sum_{j=1}^{n}\left(d_{j}-d_{j-1}\right)-\alpha_{0} t_{0}\right] Q \\
& -P \sum_{j=1}^{n}\left(d_{j}-d_{j-1}\right) V_{j-1} E\left(X-\frac{Q}{V_{j-1}}\right)^{+}
\end{aligned}
$$

Because maximizing $\Pi_{d}^{W}(Q)$ is equivalent to minimizing $C_{d}^{W}(Q)$, we concentrate on minimizing $C_{d}^{W}(Q)$, where

$$
\begin{aligned}
C_{d}^{W}(Q)= & {\left[P \sum_{j=1}^{n}\left(d_{j}-d_{j-1}\right)-\alpha_{0} t_{0}\right] Q } \\
& +P \sum_{j=1}^{n}\left(d_{j}-d_{j-1}\right) V_{j-1} E\left(X-\frac{Q}{V_{j-1}}\right)^{+} .
\end{aligned}
$$

Here, $\sum_{j=1}^{n}\left(d_{j}-d_{j-1}\right)=d_{n}$. Because the distribution $F$ of $X$ is unknown, we want to minimize $C_{d}^{W}(Q)$ against the worst possible distribution. For this, we need to use the following lemma as in Gallego and Moon [2].

Lemma 1. For any $F \in \mathbf{F}$,

$$
E[x-Q]^{+}=\frac{1}{2}\left\{\left[\sigma^{2}+(Q-\mu)^{2}\right]^{1 / 2}-(Q-\mu)\right\} .
$$

Moreover, the upper bound is tight.

Using Lemma 1, our problem now reduces to minimizing the upper bound

$$
\begin{aligned}
& C_{d}^{W}(Q)=\left(P d_{n}-\alpha_{0} t_{0}\right) Q+\frac{P}{2} \sum_{j=1}^{n}\left(d_{j}-d_{j-1}\right) \\
& \cdot V_{j-1}\left\{\left[\sigma^{2}+\left(\frac{Q}{V_{j-1}}-\mu\right)^{2}\right]^{1 / 2}-\left(\frac{Q}{V_{j-1}}-\mu\right)\right\} .
\end{aligned}
$$

The necessary condition for $Q$ to be optimal is

$$
\begin{aligned}
& \frac{d C_{d}^{W}(Q)}{d Q} \\
& =\frac{1}{2} P d_{n}-\alpha_{0} t_{0} \\
& \quad+\frac{1}{2} \sum_{j=1}^{n}\left(d_{j}-d_{j-1}\right) \frac{\left(Q / V_{j-1}-\mu\right)}{\left[\sigma^{2}+\left(Q / V_{j-1}-\mu\right)^{2}\right]^{1 / 2}}
\end{aligned}
$$

$=0$.

On simplification,

$$
\begin{aligned}
2- & \frac{2 C}{P}-d_{n} \\
& =\sum_{j=1}^{n}\left(d_{j}-d_{j-1}\right) \frac{\left(Q / V_{j-1}-\mu\right)}{\left[\sigma^{2}+\left(Q / V_{j-1}-\mu\right)^{2}\right]^{1 / 2}} .
\end{aligned}
$$

The second-order derivative of $C_{d}^{W}(Q)$ is given by $d^{2} C_{d}^{W}(Q) /$ $d Q_{2}=P \sum_{j=1}^{n}\left(\left(d_{j}-d_{j-1}\right) \sigma^{2} / V_{j-1}\left[\sigma^{2}+\left(Q / V_{j-1}-\mu\right)^{2}\right]^{3 / 2}\right)$. Because $d_{j}-d_{j-1} \geq 0, d^{2} C_{d}^{W}(Q) / d Q_{2} \geq 0$ for $Q \geq 0$ and hence $C_{d}^{W}(Q)$ is convex. Therefore, $\Pi_{d}^{W}(Q)$ is concave.

\subsection{The Newsboy Problem with Progressive Multiple Upgrades.}

We focus on the special case where the additional quality upgraded is directly proportional to the realized demand for the initial product. In other words, if the product has high demand at the regular price, then upgrading the product should result in proportionally additional demand and vice versa. If we refer to the time of the $j$ th upgrade as the $j$ th upgrade period, then statistically the demand in each upgrade period is perfectly and positively correlated with the demand in the first period. We assume that the salvage cost of the product is the $n$th upgrade cost. Here, we maximize the expected profit to compare the normal with the worst-case demand distribution. The profit function $\left(\pi_{u}^{N}(Q)\right)$ in this case can be written as

$$
\begin{aligned}
& \pi_{u}^{N}(Q) \\
& = \begin{cases}\alpha_{0} t_{0} Q & \text { if } \frac{Q}{V_{0}} \leq X \\
\alpha_{0} t_{0} X+\alpha_{1}\left(Q-V_{0} X\right) & \text { if } \frac{Q}{V_{1}} \leq X<\frac{Q}{V_{0}} \\
\alpha_{0} t_{0} X+\alpha_{1} t_{1} X+\alpha_{2}\left(Q-V_{1} X\right) & \text { if } \frac{Q}{V_{2}} \leq X<\frac{Q}{V_{1}} \\
\vdots & \vdots \\
X \sum_{j=0}^{n-1} \alpha_{j} t_{j}+\alpha_{n}\left(Q-V_{n-1} X\right) & \text { if } 0 \leq X<\frac{Q}{V_{n-1}}\end{cases}
\end{aligned}
$$


where $\alpha_{j}=P-C_{j}, V_{j}=1+\sum_{k=1}^{j} t_{k}, t_{0}=1$, and $V_{0}=1$. The expected value of $\pi_{u}^{N}(Q)$ is

$$
\begin{aligned}
& \Pi_{u}^{N}(Q)=\int_{Q / V_{0}}^{\infty} \alpha_{0} t_{0} Q f(X) d X \\
& +\int_{Q / V_{1}}^{Q / V_{0}}\left[\alpha_{0} t_{0} X+\alpha_{1}\left(Q-V_{0} X\right)\right] f(X) d X \\
& +\cdots+\int_{0}^{Q / V_{n-1}}\left[X \sum_{j=0}^{n-1} \alpha_{j} t_{j}+\alpha_{n}\left(Q-V_{n-1} X\right)\right] \\
& \quad \cdot f(X) d X .
\end{aligned}
$$

The necessary condition for $Q$ to be optimal is given by

$$
\frac{d \Pi_{u}^{N}(Q)}{d Q}=\alpha_{0}-\sum_{j=0}^{n-1}\left(C_{j+1}-C_{j}\right) F\left(\frac{Q}{V_{j}}\right)=0 .
$$

The second-order derivative of $\Pi_{u}^{N}(Q)$ is given by $d^{2} \Pi_{u}^{N}(Q) /$ $d Q_{2}=-\sum_{j=0}^{n-1}\left(1 / V_{j}\right)\left(C_{j+1}-C_{j}\right) f\left(Q / V_{j}\right)$. Because $f(X) \geq 0$ and $C_{j+1}-C_{j} \geq 0, d^{2} \Pi_{u}^{N}(Q) / d Q_{2} \leq 0$ for $Q \geq 0$ and hence $\Pi_{u}^{N}(Q)$ is concave.

Similar to the previous section, we formulate and solve the newsboy problem with multiple upgrades by the distribution-free approach. In this case, the profit function $\left(\pi_{u}^{W}(Q)\right)$ can be represented as follows:

$$
\pi_{u}^{W}(Q)= \begin{cases}\alpha_{0} t_{0} Q & \text { if } \frac{Q}{V_{0}} \leq X \\ \alpha_{0} t_{0} Q-u_{1} C\left(Q-V_{0} X\right) & \text { if } \frac{Q}{V_{1}} \leq X<\frac{Q}{V_{0}} \\ \alpha_{0} t_{0} Q-u_{1} C\left(Q-V_{0} X\right)-\left(u_{2}-u_{1}\right) C\left(Q-V_{1} X\right) & \text { if } \frac{Q}{V_{2}} \leq X<\frac{Q}{V_{1}} \\ \vdots & \vdots \\ \alpha_{0} t_{0} Q-C \sum_{j=1}^{n}\left(u_{j}-u_{j-1}\right)\left(Q-V_{j-1} X\right) & \text { if } 0 \leq \frac{Q}{V_{n-1}} .\end{cases}
$$

The expected value of $\pi_{u}^{W}(Q)$ is given by

$$
\begin{aligned}
\Pi_{u}^{W}(Q)= & \alpha_{0} t_{0} Q-C \sum_{j=1}^{n}\left(u_{j}-u_{j-1}\right) E\left(Q-V_{j-1} X\right)^{+} \\
= & \alpha_{0} t_{0} Q \\
& -C \sum_{j=1}^{n}\left(u_{j}-u_{j-1}\right) V_{j-1} E\left(\frac{Q}{V_{j-1}}-X\right)^{+} .
\end{aligned}
$$

Observing that $(Q-X)^{+}=(Q-X)+(X-Q)^{+}$, we can write the expected profit as

$$
\begin{aligned}
\Pi_{u}^{W}(Q)= & \mu C \sum_{j=1}^{n}\left(u_{j}-u_{j-1}\right) V_{j-1} \\
& -\left[C \sum_{j=1}^{n}\left(u_{j}-u_{j-1}\right)-\alpha_{0} t_{0}\right] Q \\
& -C \sum_{j=1}^{n}\left(u_{j}-u_{j-1}\right) V_{j-1} E\left(X-\frac{Q}{V_{j-1}}\right)^{+} .
\end{aligned}
$$

Because maximizing $\Pi_{u}^{W}(Q)$ is equivalent to minimizing $C_{u}^{W}(Q)$, we concentrate on minimizing $C_{u}^{W}(Q)$, where

$$
\begin{aligned}
C_{u}^{W}(Q)= & {\left[C \sum_{j=1}^{n}\left(u_{j}-u_{j-1}\right)-\alpha_{0} t_{0}\right] Q } \\
& +C \sum_{j=1}^{n}\left(u_{j}-u_{j-1}\right) V_{j-1} E\left(X-\frac{Q}{V_{j-1}}\right)^{+} .
\end{aligned}
$$

Here, $\sum_{j=1}^{n}\left(u_{j}-u_{j-1}\right)=u_{n}$. Because the distribution $F$ of $X$ is unknown, we want to minimize $C_{u}^{W}(Q)$ against the worst possible distribution. Using Lemma 1 , our problem now reduces to minimizing the upper bound

$$
\begin{aligned}
& C_{u}^{W}(Q)=\left(C u_{n}-\alpha_{0} t_{0}\right) Q+\frac{1}{2} C \sum_{j=1}^{n}\left(u_{j}-u_{j-1}\right) \\
& \cdot V_{j-1}\left\{\left[\sigma^{2}+\left(\frac{Q}{V_{j-1}}-\mu\right)^{2}\right]^{1 / 2}-\left(\frac{Q}{V_{j-1}}-\mu\right)\right\} .
\end{aligned}
$$


The necessary condition for $Q$ to be optimal is

$$
\begin{aligned}
& \frac{d C_{u}^{W}(Q)}{d Q} \\
& =\frac{1}{2} C u_{n}-\alpha_{0} t_{0} \\
& \quad+\frac{1}{2} C \sum_{j=1}^{n}\left(u_{j}-u_{j-1}\right) \frac{\left(Q / V_{j-1}-\mu\right)}{\left[\sigma^{2}+\left(Q / V_{j-1}-\mu\right)^{2}\right]^{1 / 2}} \\
& =0
\end{aligned}
$$

which gives

$$
\begin{aligned}
\frac{2 P}{C} & -2-u_{n} \\
& =\sum_{j=1}^{n}\left(u_{j}-u_{j-1}\right) \frac{\left(Q / V_{j-1}-\mu\right)}{\left[\sigma^{2}+\left(Q / V_{j-1}-\mu\right)^{2}\right]^{1 / 2}} .
\end{aligned}
$$

The second-order derivative of $C_{u}^{W}(Q)$ is given by $d^{2} C_{u}^{W}(Q) /$ $d Q_{2}=C \sum_{j=1}^{n}\left(\left(u_{j}-u_{j-1}\right) \sigma^{2} / V_{j-1}\left[\sigma^{2}+\left(Q / V_{j-1}-\mu\right)^{2}\right]^{3 / 2}\right)$. Because $u_{j}-u_{j-1} \geq 0, d^{2} C_{u}^{W}(Q) / d Q_{2} \geq 0$ for $Q \geq 0$ and hence $C_{u}^{W}(Q)$ is convex. Therefore, $\Pi_{u}^{W}(Q)$ is concave.

2.3. The Mixed Newsboy Problem with Progressive Multiple Discounts and Upgrades. Multiple discounts lead to higher order quantities compared to the one found in the classical newsboy problems because multiple discounts result in increased demand at prices that are higher than the salvage value in the classical newsboy problem. More practically, the discount policy is not the only way to sell excess products. Sellers make additional investment in marketing to attract more customers to stores through progressive discounts. Bridson et al. [39] suggested that an appropriate mix of hard attributes (discounts and coupons) and soft attributes (better service, upgrades, and special attention) can affect customer satisfaction with stores. Therefore, when considering the mixed model with progressive multiple discounts and upgrades (i.e., multiple discounts with progressively increasing costs), the profit function of the model is given by

$$
\begin{aligned}
\pi_{d u}^{W}(Q) & \left\{\begin{array}{lr}
\alpha_{0} t_{0} Q & \text { if } \frac{Q}{V_{0}} \leq X \\
\alpha_{0} t_{0} Q-d_{1} P\left(Q-V_{0} X\right) & \text { if } \frac{Q}{V_{1}} \leq X<\frac{Q}{V_{0}} \\
\alpha_{0} t_{0} Q-d_{1} P\left(Q-V_{0} X\right)-u_{1} C\left(Q-V_{1} X\right) & \text { if } \frac{Q}{V_{2}} \leq X<\frac{Q}{V_{1}} \\
\alpha_{0} t_{0} Q-d_{1} P\left(Q-V_{0} X\right)-u_{1} C\left(Q-V_{1} X\right)-\left(d_{2}-d_{1}\right) P\left(Q-V_{2} X\right) & \text { if } \frac{Q}{V_{3}} \leq X<\frac{Q}{V_{2}} \\
\alpha_{0} t_{0} Q-d_{1} P\left(Q-V_{0} X\right)-u_{1} C\left(Q-V_{1} X\right)-\left(d_{2}-d_{1}\right) P\left(Q-V_{2} X\right)-\left(u_{2}-u_{1}\right) C\left(Q-V_{3} X\right) & \text { if } \frac{Q}{V_{4}} \leq X<\frac{Q}{V_{3}} \\
\vdots & \vdots \\
\alpha_{0} t_{0} Q-P \sum_{j=1}^{n}\left(d_{j}-d_{j-1}\right)\left(Q-V_{2(j-1)} X\right)-C \sum_{j=1}^{n}\left(u_{j}-u_{j-1}\right)\left(Q-V_{2 j-1} X\right) & \text { if } 0 \leq X<\frac{Q}{V_{n-1}}
\end{array}\right.
\end{aligned}
$$

where $\alpha_{j}=P_{j}-C_{j}$ and $V_{j}=1+\sum_{k=1}^{j} t_{k}, t_{0}=1$, and $V_{0}=1$. The expected value of $\pi_{d u}^{W}(Q)$ is

$$
\begin{aligned}
& \Pi_{d u}^{W}(Q) \\
& =\alpha_{0} t_{0} Q-P \sum_{j=1}^{n}\left(d_{j}-d_{j-1}\right) E\left(Q-V_{2(j-1)} X\right)^{+} \\
& \quad-C \sum_{j=1}^{n}\left(u_{j}-u_{j-1}\right) E\left(Q-V_{2 j-1} X\right)^{+} \\
& =\alpha_{0} t_{0} Q
\end{aligned}
$$

$$
\begin{aligned}
& -P \sum_{j=1}^{n}\left(d_{j}-d_{j-1}\right) V_{2(j-1)} E\left(\frac{Q}{V_{2(j-1)}}-X\right)^{+} \\
& -C \sum_{j=1}^{n}\left(u_{j}-u_{j-1}\right) V_{2 j-1} E\left(\frac{Q}{V_{2 j-1}}-X\right)^{+} .
\end{aligned}
$$

Observing that $(Q-X)^{+}=(Q-X)+(X-Q)^{+}$, we can write the expected profit as

$$
\begin{aligned}
& \Pi_{d u}^{W}(Q) \\
& \quad=\mu P \sum_{j=1}^{n}\left(d_{j}-d_{j-1}\right) V_{2(j-1)}
\end{aligned}
$$




$$
\begin{aligned}
& +\mu C \sum_{j=1}^{n}\left(u_{j}-u_{j-1}\right) V_{2 j-1}-P Q \sum_{j=1}^{n}\left(d_{j}-d_{j-1}\right) \\
& -C Q \sum_{j=1}^{n}\left(u_{j}-u_{j-1}\right) \\
& -P \sum_{j=1}^{n}\left(d_{j}-d_{j-1}\right) V_{2(j-1)} E\left(X-\frac{Q}{V_{2(j-1)}}\right)^{+} \\
& -C \sum_{j=1}^{n}\left(u_{j}-u_{j-1}\right) V_{2 j-1} E\left(X-\frac{Q}{V_{2 j-1}}\right)^{+} \\
& +\alpha_{0} t_{0} Q .
\end{aligned}
$$

In the distribution-free approach, maximizing $\Pi_{d u}^{W}(Q)$ is equivalent to minimizing $C_{d u}^{W}(Q)$; we concentrate on minimizing $C_{d u}^{W}(Q)$, where

$$
\begin{aligned}
C_{d u}^{W}(Q) & \\
= & P Q \sum_{j=1}^{n}\left(d_{j}-d_{j-1}\right)+C Q \sum_{j=1}^{n}\left(u_{j}-u_{j-1}\right) \\
& +P \sum_{j=1}^{n}\left(d_{j}-d_{j-1}\right) V_{2(j-1)} E\left(X-\frac{Q}{V_{2(j-1)}}\right)^{+} \\
& -\alpha_{0} t_{0} Q \\
& +C \sum_{j=1}^{n}\left(u_{j}-u_{j-1}\right) V_{2 j-1} E\left(X-\frac{Q}{V_{2 j-1}}\right)^{+} .
\end{aligned}
$$

Because the distribution $F$ of $X$ is unknown, we want to minimize $C_{d u}^{W}(Q)$ against the worst possible distribution. Using Lemma 1, our problem now reduces to minimizing the upper bound

$$
\begin{aligned}
& C_{d u}^{W}(Q)=P Q \sum_{j=1}^{n}\left(d_{j}-d_{j-1}\right)+C Q \sum_{j=1}^{n}\left(u_{j}-u_{j-1}\right) \\
& -\alpha_{0} t_{0} Q+\frac{1}{2} P \sum_{j=1}^{n}\left(d_{j}-d_{j-1}\right) \\
& \cdot V_{2(j-1)}\left\{\left[\sigma^{2}+\left(\frac{Q}{V_{2(j-1)}}-\mu\right)^{2}\right]^{1 / 2}\right. \\
& \left.+\left(\frac{Q}{V_{2(j-1)}}-\mu\right)\right\}+\frac{1}{2} C \sum_{j=1}^{n}\left(u_{j}-u_{j-1}\right) \\
& +V_{2 j-1}\left\{\left[\sigma^{2}+\left(\frac{Q}{V_{2 j-1}}-\mu\right)^{2}\right]^{1 / 2}\right. \\
& \left.+\left(\frac{Q}{V_{2 j-1}}-\mu\right)\right\} \cdot
\end{aligned}
$$

The necessary condition for $Q$ to be optimal is $d C_{d u}^{W}(Q) / d Q=$ 0 , which gives

$$
\begin{aligned}
& 2 \alpha_{0} t_{0}-P d_{n}-C u_{n} \\
& =\frac{1}{2} C \sum_{j=1}^{n}\left(u_{j}-u_{j-1}\right) \frac{\left(Q / V_{2 j-1}-\mu\right)}{\left[\sigma^{2}+\left(Q / V_{2 j-1}-\mu\right)^{2}\right]^{1 / 2}} \\
& \quad+\frac{1}{2} P \sum_{j=1}^{n}\left(d_{j}-d_{j-1}\right) \frac{\left(Q / V_{2(j-1)}-\mu\right)}{\left[\sigma^{2}+\left(Q / V_{2(j-1)}-\mu\right)^{2}\right]^{1 / 2}} .
\end{aligned}
$$

The second-order derivative of $C_{d u}^{W}(Q)$ is given by

$$
\begin{aligned}
& \frac{d^{2} C_{d u}^{W}(Q)}{d Q_{2}}=C \sum_{j=1}^{n}\left(\frac{1}{V_{2 j-1}}\right)\left(u_{j}-u_{j-1}\right) \\
& \cdot \frac{\sigma^{2}}{\left[\sigma^{2}+\left(Q / V_{2 j-1}-\mu\right)^{2}\right]^{3 / 2}}+P \sum_{j=1}^{n}\left(\frac{1}{V_{2(j-1)}}\right) \\
& \cdot\left(d_{j}-d_{j-1}\right) \frac{\sigma^{2}}{\left[\sigma^{2}+\left(Q / V_{2(j-1)}-\mu\right)^{2}\right]^{3 / 2}} .
\end{aligned}
$$

Because $u_{j}-u_{j-1} \geq 0$ and $d_{j}-d_{j-1} \geq 0, d^{2} C_{d u}^{W}(Q) / d Q_{2} \geq 0$ for $Q \geq 0$ and hence $C_{d u}^{W}(Q)$ is convex. Therefore, $\Pi_{d u}^{W}(Q)$ is concave.

The optimality of the solution for the normal distribution expected-profit model can be verified by the same method mentioned above. Hence, the detailed discussion is omitted.

\section{The Newsboy Problem with Progressive Multiple Discounts with a Budget or a Storage Constraint}

The purpose of this section is to investigate the effect of a budget or a storage constraint on the optimal order quantities in a multiproduct newsboy problem in which multiple discounts or upgrades are used to sell excess inventory. The following additional notations are used in this section to develop the newsboy problem applied to multiple products:

$i$ : the product index.

$I$ : the number of products.

$j:$ the discounted index.

$n$ : the number of discounts offered.

$P_{i}$ : the unit selling price offered for product $i$.

$C_{i}$ : the unit cost offered for product $i$.

$S_{i}$ : the salvage value offered for product $i$.

$d_{i, j}$ : the $j$ th discounted rate for product $i$

$\left(0 \leq d_{i, j} \leq 1\right), 0=d_{i, 0}<d_{i, 1}<d_{i, 2}<\cdots<d_{i, n}$.

$P_{i, j}$ : the $j$ th discounted selling price for product $i$, $P_{i, j}=\left(1-d_{i, j}\right) P_{i}$. 
$\mu_{i}$ : the expected demand for product $i$.

$\sigma_{i}$ : the standard deviation of demand for product $i$.

$k_{i}$ : the storage space needed per unit of product $i$.

$Q_{i}$ : the order quantity for product $i$.

$t_{i, j}$ : the fraction of the realized demand of product $i$ at the original price that can additionally be sold by discounting the product to price $P_{i, j}$.

$K$ : the total storage capacity.

$B$ : the budget for the period.

For the multiproduct problem, the total expected profit $\left(E_{d}(Z)\right)$ under progressive multiple discount is obtained by considering the sum of the expected profits for all products as follows:

$$
E_{d}(Z)=\sum_{j=1}^{I} E_{d}\left(\pi_{i}\right),
$$

where $E_{d}\left(\pi_{i}\right)$ is the expected profit from the $i$ th product. Under the multiproduct problem, we have the following constraint optimization problems.

Problem 1. Maximizing the expected profit under a storage constraint,

$$
\begin{aligned}
\operatorname{Max} & E_{d}(Z) \\
\text { Subject to } & \sum_{j=1}^{I} k_{i} Q_{i} \leq K, \quad Q_{i} \geq 0, i=1,2, \ldots, I .
\end{aligned}
$$

Problem 2. Maximizing the expected profit under a budget constraint,

$$
\begin{aligned}
\operatorname{Max} & E_{d}(Z) \\
\text { Subject to } & \sum_{j=1}^{I} C_{i} Q_{i} \leq B, \quad Q_{i} \geq 0, \quad i=1,2, \ldots, I .
\end{aligned}
$$

We concentrate on problem 1 (P1) due to the heavy similarities between the formulations of (P1) and (P2). All the following results apply to problem 2 (P2) by replacing $k_{i}$ and $K$ with $C_{i}$ and $B$, respectively. The necessary conditions for $Q_{i}(i=1,2, \ldots, I)$ to be optimal are as follows.

In the traditional approach,

$$
\begin{aligned}
\frac{\partial E_{d}(Z)}{\partial Q_{i}} & =\alpha_{0}-\sum_{j=0}^{n-1}\left(P_{i, j}-P_{i, j+1}\right) F\left(\frac{Q_{i}}{V_{i, j}}\right)-\lambda_{1} k_{i} \\
& =0, \quad \forall i .
\end{aligned}
$$

In the distribution-free approach,

$$
\begin{aligned}
& \frac{\partial C_{d}(Z)}{\partial Q_{i}}=\frac{2 C_{i}}{P_{i}}+d_{i, n}-2 \\
& +\sum_{j=1}^{n}\left(d_{i, j}-d_{i, j-1}\right) \frac{\left(Q_{i} / V_{i, j-1}-\mu_{i}\right)}{\left[\sigma_{i}^{2}+\left(Q_{i} / V_{i, j-1}-\mu_{i}\right)^{2}\right]^{1 / 2}} \\
& \quad-\frac{2 \lambda_{1} k_{i}}{P_{i}}=0, \quad \forall i,
\end{aligned}
$$

where $\lambda_{1}(>0)$ is the Lagrange multiplier and $C_{d}(Z)$ is the cost function under the distribution-free approach. Algorithm 1 is used to find the optimal $Q_{i}, i=1,2, \ldots, I$.

\section{Algorithm 1.}

Step 1. Find $Q_{i}, i=1,2, \ldots, I$, using an unconstrained solution.

If $\sum_{j=1}^{I} k_{i} Q_{i} \leq K$, the solution is optimal.

Otherwise, set $\lambda_{1 U}=\operatorname{Max}\left[\left(P_{i, 0}-C_{i}\right) / k_{i}\right]$ and $\lambda_{1 L}=0$

and go to Step 2.

Step 2. Set a sufficiently small computational accuracy parameter $\epsilon>0$.

Set $\lambda_{1 M}=\left(\lambda_{1 U}+\lambda_{1 L}\right) / 2$. Using $\lambda_{1 L}$, solve (30) or (31) for $i=1,2, \ldots, I$.

If no solution exists for product $i$, set $Q_{i}=0$.

Otherwise, find $Q_{i}$ and go to Step 3 .

Step 3. If $\sum_{j=1}^{I} k_{i} Q_{i}>K$, set $\lambda_{1 L}=\lambda_{1 M}$ and go to Step 2 .

If $\sum_{j=1}^{I} k_{i} Q_{i}<K, \lambda_{1 U}-\lambda_{1 M}>\epsilon$ are satisfied.

Set $\lambda_{U}=\lambda_{M}$

Go to Step 2.

Otherwise, the solution is optimal.

Similarly, we can formulate the newsboy problem with progressive multiple upgrades with a budget or storage constraint. The necessary conditions for $Q_{i}(i=1,2, \ldots, I)$ to be optimal under progressive multiple upgrades are as follows.

In the traditional approach,

$$
\begin{aligned}
\frac{\partial E_{u}(Z)}{\partial Q_{i}} & =\alpha_{0}-\sum_{j=0}^{n-1}\left(C_{i, j+1}-C_{i, j}\right) F\left(\frac{Q_{i}}{V_{i, j}}\right)-\lambda_{1} k_{i} \\
& =0, \quad \forall i .
\end{aligned}
$$

In the distribution-free approach,

$$
\begin{aligned}
& \frac{\partial C_{u}(Z)}{\partial Q_{i}}=\frac{2 P_{i}}{C_{i}}-u_{i, n}-2 \\
& \quad+\sum_{j=1}^{n}\left(u_{i, j}-u_{i, j-1}\right) \frac{\left(Q_{i} / V_{i, j-1}-\mu_{i}\right)}{\left[\sigma_{i}^{2}+\left(Q_{i} / V_{i, j-1}-\mu_{i}\right)^{2}\right]^{1 / 2}} \\
& \quad-\frac{2 \lambda_{1} k_{i}}{C_{i}}=0, \quad \forall i .
\end{aligned}
$$

The computational results for all four scenarios are shown in the following section.

\section{Numerical Examples}

In this section, we provide numerical illustration on how the expected profits under the general and the distribution-free approaches are affected by various cases by using the models developed in Sections 2 and 3. 
Example 1. We consider a product with a regular unit price and a constant unit cost. Discounts of $10 \%, 20 \%, 30 \%, 40 \%$, and $50 \%$ off the regular price are progressively used to sell excess inventory. We also assume that a fraction of the original demand will be realized as additional sales at each of the first four discounted prices: $t_{1}=0.1, t_{2}=0.1, t_{3}=0.2$, and $t_{4}=0.3$. Furthermore, we assume that an unlimited quantity can be sold at the fifth discount price. In addition, $P=\$ 10$ per unit, $C=\$ 7.5$ per unit, $S=\$ 5$ per unit, $\mu=100$ unit, and $\sigma=15$ unit. We compare the performance of $Q_{d}^{N}$ with $Q_{d}^{W}$. The results are (normal distribution in parenthesis) $Q_{d}^{W}=122.0732$ units $\left(Q_{n}^{N}=122.5361\right.$ units $)$ and a worst-case expected profit of $\Pi_{d}^{W}(Q)=\$ 257.4775\left(\Pi_{d}^{N}=\$ 257.4845\right)$. The Expected Value of Additional Information (EVAI) is $\$ 0.007$. Additionally, if the management did not consider multiple discounts and immediately discounted the product's price from $\$ 10$ to $\$ 5$, the optimal quantity would be the same compared to the result from the classical newsboy problem of 100 units with the corresponding expected profit of $\$ 154.89$. Therefore, we show that progressive multiple discounts are profitable for the seller.

Example 2. We use the same data as in Example 1 for comparison. In this example, we consider a product with a regular unit cost and a constant unit price. Upgrades of $13.33 \%, 26.67 \%, 40 \%, 53.33 \%$, and $66.67 \%$, added without increasing the cost, are progressively used to sell excess inventory. We also assume that a fraction of the original demand will be realized as additional sales at each of the first four upgrade costs: $t_{1}=0.1, t_{2}=0.1, t_{3}=0.2$, and $t_{4}=0.3$. An unlimited quantity can be sold at the salvage value. The results show (normal distribution in parenthesis) $Q_{u}^{W}=122.0732$ units $\left(Q_{u}^{N}=122.5361\right.$ units $)$ and a worstcase expected profit of $\Pi_{u}^{W}(Q)=\$ 257.4775\left(\Pi_{u}^{N}=\$ 257.4845\right)$. The value of EVAI is $\$ 0.007$. The model with discounts is equivalent to the model with upgrades. Therefore, if the impacts of discounts and upgrades are uniform, then the seller can use either strategy to increase profit.

Example 3. We use the same data as in Example 1 for comparison. We consider discounts of $10 \%, 20 \%, 30 \%, 40 \%$, and $50 \%$ off the regular price and upgrades of 5\%, 10\%, 15\%, and $20 \%$ are progressively used, with no increase in price, to sell excess inventory. We assume that management offers four discounts and four upgrades before offering the product at salvage value. The first discount is $10 \%$ off the original price and results in $10 \%$ additional sales $\left(t_{1}=0.1\right)$, and the first upgrade is $5 \%$ of the original cost and results in $5 \%$ additional sales $\left(t_{2}=0.05\right)$. The second discount is $20 \%$ off the original price and results in $10 \%$ additional sales $\left(t_{3}=0.1\right)$, and the second upgrade is $10 \%$ of the original cost and results in $5 \%$ additional sales $\left(t_{4}=0.05\right)$. The third discount is $30 \%$ off the original price and results in $20 \%$ additional sales $\left(t_{5}=\right.$ 0.2 ). The third upgrade is $15 \%$ of the original cost and results in $10 \%$ additional sales $\left(t_{6}=0.1\right)$. The fourth discount is $40 \%$ off the original price and results in $30 \%$ additional sales $\left(t_{7}=0.3\right)$. The fourth upgrade is $20 \%$ of the original cost and results in $15 \%$ additional sales $\left(t_{8}=0.15\right)$, while unlimited quantity can be sold at the salvage value. The results show (normal distribution in parenthesis) $Q_{d u}^{W}=121.5615\left(Q_{d u}^{N}=\right.$ 122.2547) and a worst-case expected profit of $\Pi_{d u}^{W}(Q)=$ $\$ 258.4478\left(\Pi_{d u}^{N}=\$ 258.4653\right)$. The value of EVAI is $\$ 0.0174$.

Examples 1, 2, and 3 show that the expected profit is increased and the order quantity is decreased when the seller applies both discounts and upgrades. Therefore, we can conclude that simultaneous discounts and upgrades may profit the seller.

Example 4. We consider a newsboy problem with five products. The total space available for the products is $7000 \mathrm{ft}^{3}$. We assume that, for each product, the management offers two discounts before offering the product at salvage value. The first discount is $10 \%$ off the original price and results in $10 \%$ additional sales $\left(t_{i, 1}=0.1\right)$, and the second discount is $25 \%$ off the original price and results in $20 \%$ additional sales $\left(t_{i, 2}=\right.$ 0.2 ). Unlimited quantity can be sold at the third discount price. The third discount on items 1 and 5 is $50 \%$ off the original price, while it is $35 \%$ off on item $2,45.5 \%$ off on item 3 , and approximately $53.1 \%$ off on item 4 . The optimal results for the normally distributed demand and unknown distributed demand are shown in Table 1.

First, we solve the unconstrained problem. The total space required for this problem is $14,251 \mathrm{ft}^{3}$ which exceeds the total available space. The total expected profit for the worst case and the normal distribution is \$34111.05 and \$34111.26, respectively. The value of EVAI is $\$ 0.21$. Using the proposed algorithm (Algorithm 1), we start with $\lambda_{1 U}=6.47$, which is $\operatorname{Max}\left[\left(P_{i, 0}-C_{i}\right) / k_{i}\right]$ for Product 4 . Under the normal distribution of demand, the optimal value of $\lambda_{1}$ is $\lambda_{1}^{*}=1.8916$, and, under the distribution-free approach, the optimal value is $\lambda_{1}^{*}=1.8186$. The new optimal solution demonstrates that, under the normal distribution demand, total storage of $7000 \mathrm{ft}^{3}$ (sum of the 11th row) is needed, and, under the distribution-free approach, total storage of $6999.82 \mathrm{ft}^{3}$ is needed. The total expected profit for the normal distribution and the worst case is $\$ 24439.74$ and $\$ 24436.73$, respectively. The value of EVAI is \$3.01. Moreover, from Example 4, we conclude that the ordering decision determined by the newsboy problem in the multiple-item environment is highly influenced by an additional constraint. Finally, all of the above examples demonstrate the robustness of the distribution-free approach.

\section{Concluding Remarks}

Motivated by the discounts and the quality upgrade strategy practices in the real world, we extend and derive the optimal ordering rule for the newsboy problem with multiple discounts, multiple upgrades, and the combined uses of both strategies in single- and multiple-item environments. We adopt the distribution-free approach where only available information is the mean and standard deviation of demand and compare the results with those found through the traditional approach. We conclude that the distribution-free approach is robust from computational results. Experiments with numerical data under an identical environment indicate 
TABLE 1: Data and the optimal results for the basic and distribution-free model with a storage constraint.

\begin{tabular}{|c|c|c|c|c|c|c|}
\hline & Parameter & 1 & 2 & 3 & 4 & 5 \\
\hline & $P_{i}$ & 120 & 100 & 220 & 160 & 130 \\
\hline & $C_{i}$ & 80 & 75 & 170 & 105 & 100 \\
\hline & $S_{i}$ & $60(0.5)$ & $65(0.35)$ & $120(0.455)$ & $75(0.531)$ & $65(0.5)$ \\
\hline & $\mu_{i}$ & 200 & 250 & 120 & 150 & 180 \\
\hline & $\sigma_{i}$ & 40 & 50 & 15 & 30 & 40 \\
\hline & $k_{i}$ & 21 & 7 & 12 & 8.5 & 16.25 \\
\hline \multirow{4}{*}{$\begin{array}{l}\text { Without } \\
\text { storage } \\
\text { constraint }\end{array}$} & $Q_{i}^{N}$ & 257.57 & 315.46 & 138.82 & 192.18 & 205.20 \\
\hline & $Q_{i}^{W}$ & 257.40 & 314.33 & 138.80 & 192.15 & 205.84 \\
\hline & $\pi_{i}^{N}\left(Q_{i}^{N}\right)$ & 8246.49 & 6277.35 & 6071.14 & 8495.51 & 5020.77 \\
\hline & $\pi_{i}^{W}\left(Q_{i}^{W}\right)$ & 8246.49 & 6277.24 & 6071.14 & 8495.51 & 5020.67 \\
\hline \multirow{4}{*}{$\begin{array}{l}\text { With } \\
\text { storage } \\
\text { constraint }\end{array}$} & $Q_{i}^{N}$ & 107.94 & 253.05 & 124.89 & 172.14 & 0 \\
\hline & $Q_{i}^{W}$ & 105.86 & 257.18 & 125.14 & 173.50 & 0 \\
\hline & $\pi_{i}^{N}\left(Q_{i}^{N}\right)$ & 4313.66 & 5876.84 & 5911.79 & 8337.45 & 0 \\
\hline & $\pi_{i}^{W}\left(Q_{i}^{W}\right)$ & 4231.19 & 5929.64 & 5917.35 & 8358.55 & 0 \\
\hline
\end{tabular}

that a greater number of discounts and upgrades are associated with greater expected profits. The result offers a novel addition to the literature on the newsboy problem.

The study proposes several directions for future research. The developed model under a multiple-item scenario assumes the presence of independent demand and the influence of discounts or upgrades for various products. Therefore, we encourage the development of a new approach where researchers also consider demand substitution effect and price-dependent demand as well as bundle discounts under various distribution functions. In addition, researchers may extend all the models in the supply chain framework to study the effect of bargaining power of channel members on discounts or upgrades.

\section{Competing Interests}

The authors declare that they have no competing interests.

\section{Acknowledgments}

This research was supported by the National Research Foundation of Korea (NRF) funded by the Ministry of Science, ICT \& Future Planning (2015R1A2A1A15053948).

\section{References}

[1] H. Scarf, "A min max solution of an inventory problem," in Studies in the Mathematical Theory of Inventory and Production, pp. 201-209, Stanford University Press, Stanford, Calif, USA, 1958.

[2] G. Gallego and I. Moon, "The distribution free newsboy problem: review and extensions," Journal of the Operational Research Society, vol. 44, no. 8, pp. 825-834, 1993.

[3] I. Moon and G. Gallego, "Distribution free procedures for some inventory models," Journal of the Operational Research Society, vol. 45 , no. 6 , pp. 651-658, 1994.
[4] I. Moon and S. Choi, "The distribution free continuous review inventory system with a service level constraint," Computers and Industrial Engineering, vol. 27, no. 1-4, pp. 209-212, 1994.

[5] I. Moon and S. Choi, "Distribution free procedures for maketo-order (MTO), make-in-advance (MIA), and composite policies," International Journal of Production Economics, vol. 48, no. 1, pp. 21-28, 1997.

[6] I. Moon and S. Choi, "A note on lead time and distributional assumptions in continuous review inventory models," Computers and Operations Research, vol. 25, no. 11, pp. 1007-1012, 1998.

[7] L.-Y. Ouyang and K.-S. Wu, "A minimax distribution free procedure for mixed inventory model with variable lead time," International Journal of Production Economics, vol. 56-57, pp. 511-516, 1998.

[8] M. Hariga and M. Ben-Daya, "Some stochastic inventory models with deterministic variable lead time," European Journal of Operational Research, vol. 113, no. 1, pp. 42-51, 1999.

[9] L.-Y. Ouyang and H.-C. Chang, "A minimax distribution free procedure for mixed inventory models involving variable lead time with fuzzy lost sales," International Journal of Production Economics, vol. 76, no. 1, pp. 1-12, 2002.

[10] M. M. Tajbakhsh, "On the distribution free continuous-review inventory model with a service level constraint," Computers \& Industrial Engineering, vol. 59, no. 4, pp. 1022-1024, 2010.

[11] I. Moon, E. Shin, and B. Sarkar, "Min-max distribution free continuous-review model with a service level constraint and variable lead time," Applied Mathematics and Computation, vol. 229, pp. 310-315, 2014.

[12] J. Kamburowski, "On the distribution-free newsboy problem with some non-skewed demands," Operations Research Letters, vol. 43, no. 2, pp. 165-171, 2015.

[13] M.-H. Shu, C.-W. Yeh, and Y.-C. Fu, "Impacts of transportation cost on distribution-free newsboy problems," Mathematical Problems in Engineering, vol. 2014, Article ID 307935, 10 pages, 2014.

[14] W.-M. Ma and B.-B. Qiu, "Distribution-free continuous review inventory model with controllable lead time and setup cost in 
the presence of a service level constraint," Mathematical Problems in Engineering, vol. 2012, Article ID 867847, 16 pages, 2012.

[15] H. Bidkhori, D. Simchi-Levi, and Y. Wei, "Analyzing process flexibility: a distribution-free approach with partial expectations," Operations Research Letters, vol. 44, no. 3, pp. 291-296, 2016.

[16] K. Kwon and T. Cheong, "A minimax distribution-free procedure for a newsvendor problem with free shipping," European Journal of Operational Research, vol. 232, no. 1, pp. 234-240, 2014.

[17] Y. Qin, R. Wang, A. J. Vakharia, Y. Chen, and M. M. H. Seref, "The newsvendor problem: review and directions for future research," European Journal of Operational Research, vol. 213, no. 2, pp. 361-374, 2011.

[18] G. Hadley and T. M. Whitin, Analysis of Inventory Systems, Prentice-Hall, Englewood Cliffs, NJ, USA, 1963.

[19] E. Carrizosa, A. V. Olivares-Nadal, and P. Ramírez-Cobo, "Robust newsvendor problem with autoregressive demand," Computers and Operations Research, vol. 68, pp. 123-133, 2016.

[20] Q. Li, C. Dong, and R. Zhuang, "Managing the newsvendor modeled product system with random capacity and capacitydependent price," Mathematical Problems in Engineering, vol. 2015, Article ID 296132, 10 pages, 2015.

[21] T. Ye and H. Sun, "Price-setting newsvendor with strategic consumers," Omega, vol. 63, pp. 103-110, 2016.

[22] N. C. Petruzzi and M. Dada, "Pricing and the newsvendor problem: a review with extensions," Operations Research, vol. 47, no. 2, pp. 183-194, 1999.

[23] H. Chen and A. R. Rao, "When two plus two is not equal to four: errors in processing multiple percentage changes," Journal of Consumer Research, vol. 34, no. 3, pp. 327-340, 2007.

[24] M. Khouja, "The newsboy problem under progressive multiple discounts," European Journal of Operational Research, vol. 84, no. 2, pp. 458-466, 1995.

[25] M. Khouja and A. Mehrez, "A multi-product constrained newsboy problem with progressive multiple discounts," Computers \& Industrial Engineering, vol. 30, no. 1, pp. 95-101, 1996.

[26] M. J. Khouja, "Optimal ordering, discounting, and pricing in the single-period problem," International Journal of Production Economics, vol. 65, no. 2, pp. 201-216, 2000.

[27] I. Moon and E. A. Silver, "The multi-item newsvendor problem with a budget constraint and fixed ordering costs," Journal of the Operational Research Society, vol. 51, no. 5, pp. 602-608, 2000.

[28] L. L. Abdel-Malek and R. Montanari, "An analysis of the multi-product newsboy problem with a budget constraint," International Journal of Production Economics, vol. 97, no. 3, pp. 296-307, 2005.

[29] G. Zhang, "The multi-product newsboy problem with supplier quantity discounts and a budget constraint," European Journal of Operational Research, vol. 206, no. 2, pp. 350-360, 2010.

[30] S. Nahmias and C. P. Schmidt, "An efficient heuristic for the multi-item newsboy problem with a single constraint," Naval Research Logistics, vol. 31, no. 3, pp. 463-474, 1984.

[31] H.-S. Lau and A. H.-L. Lau, "The newsstand problem: a capacitated multiple-product single-period inventory problem," European Journal of Operational Research, vol. 94, no. 1, pp. 29-42, 1996.

[32] S. J. Erlebacher, "Optimal and heuristic solutions for the multiitem newsvendor problem with a single capacity constraint," Production and Operations Management, vol. 9, no. 3, pp. 303318, 2000.
[33] M. Mussa and S. Rosen, "Monopoly and product quality," Journal of Economic Theory, vol. 18, no. 2, pp. 301-317, 1978.

[34] D. A. Garvin, "What does product quality really mean," MIT Sloan Management Review, vol. 26, pp. 25-43, 1984.

[35] Toyota, "New initiatives for quality improvement," Toyko, 2012, http://www.toyota-global.com/company/history_of_toyota/ 75years/text/entering_the_automotive_business/chapter2/section1/item3.html.

[36] L. A. Crosby, K. R. Evans, and D. Cowles, "Relationship quality in services selling: an interpersonal influence perspective," Journal of Marketing, vol. 54, no. 3, pp. 68-81, 1990.

[37] X. Xu, "Optimal price and product quality decisions in a distribution channel," Management Science, vol. 55, no. 8, pp. 13471352, 2009.

[38] P. Ma, H. Wang, and J. Shang, "Supply chain channel strategies with quality and marketing effort-dependent demand," International Journal of Production Economics, vol. 144, no. 2, pp. 572581, 2013.

[39] K. Bridson, J. Evans, and M. Hickman, "Assessing the relationship between loyalty program attributes, store satisfaction and store loyalty," Journal of Retailing and Consumer Services, vol. 15, no. 5, pp. 364-374, 2008. 


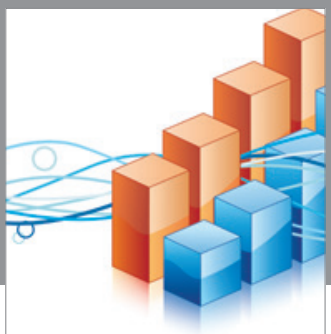

Advances in

Operations Research

vatem alat4

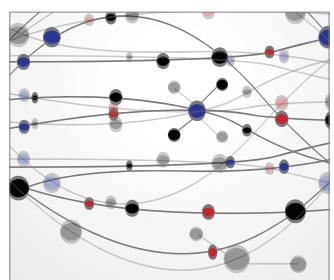

\section{The Scientific} World Journal
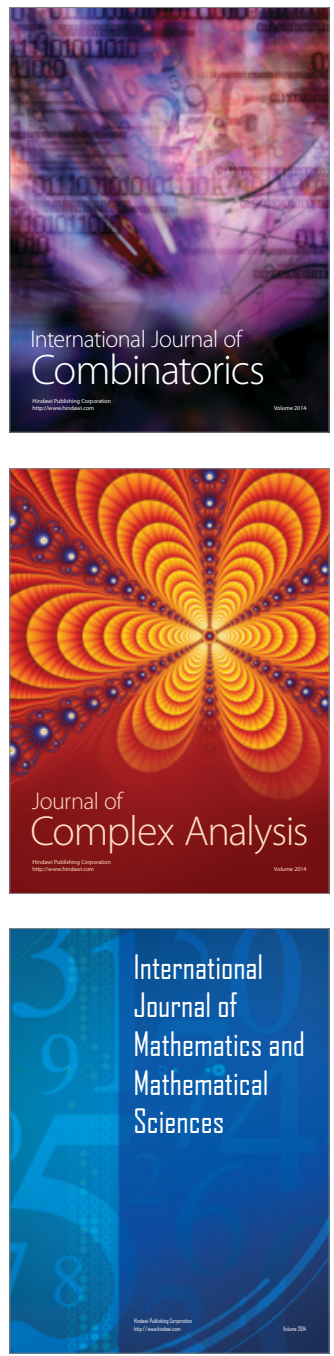
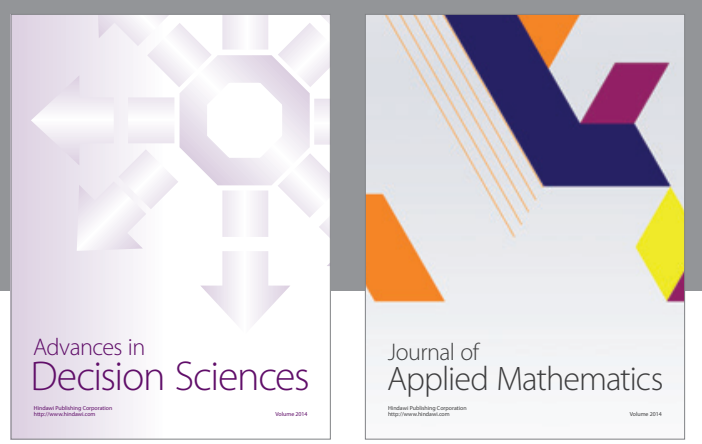

Algebra

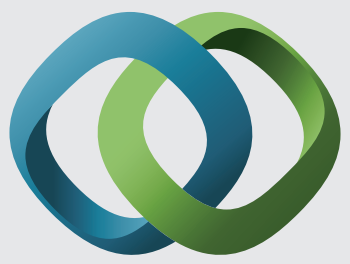

\section{Hindawi}

Submit your manuscripts at

http://www.hindawi.com
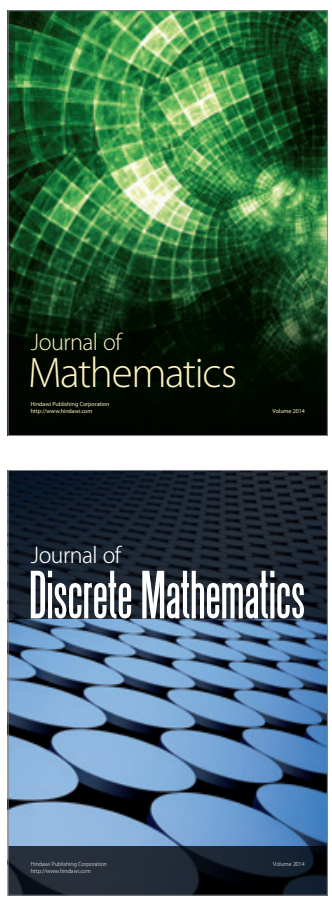

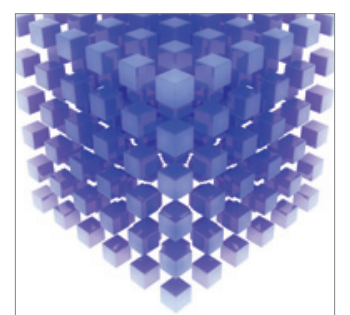

Mathematical Problems in Engineering
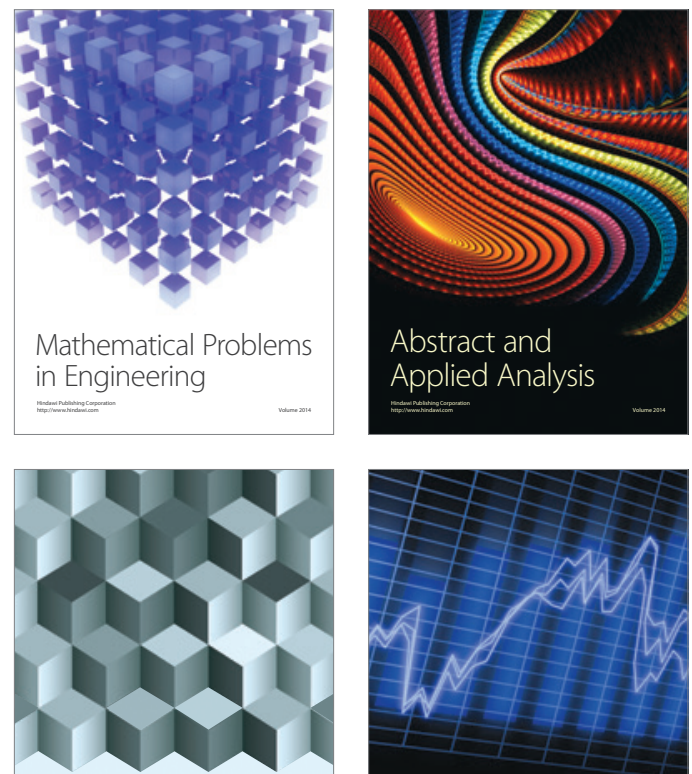

Journal of

Function Spaces

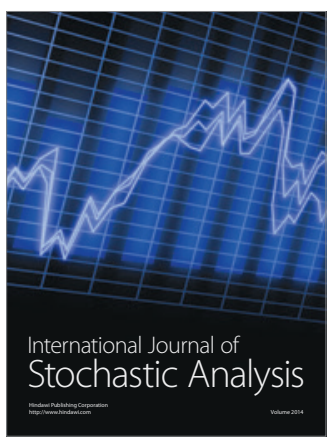

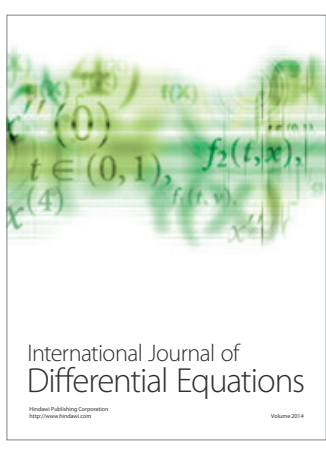
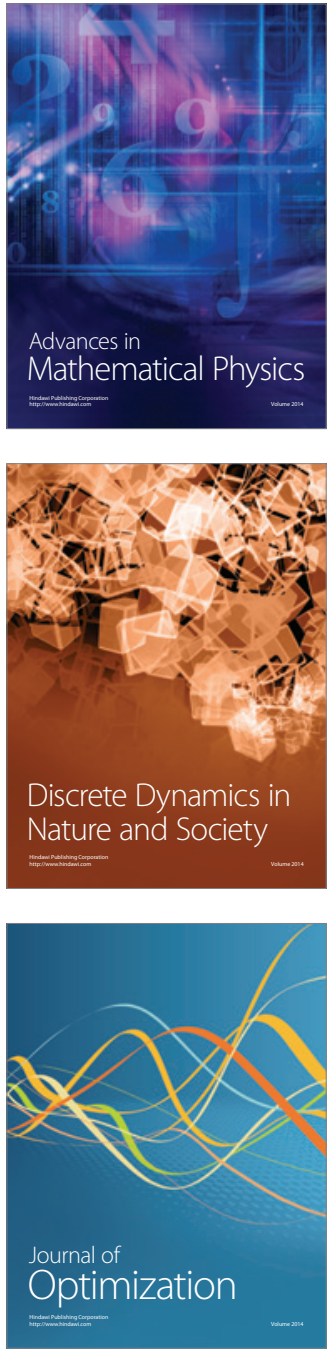